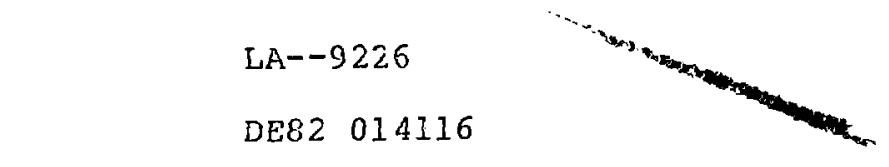

\title{
Reentry Thermal Testing of Light-Weight Radioisotope Heater Units
}

\author{
D. E. Peterson \\ J. S. Starzynski
}

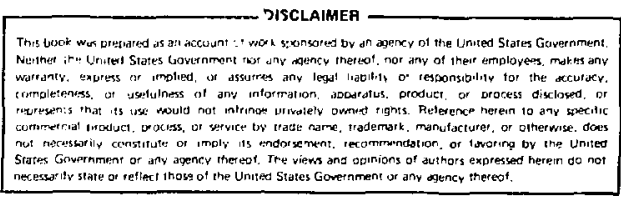




\title{
REENTRY THERMAL TESTING
}

of

\section{LIGHT-WEIGHT RADIOISOTOPE HEATER UNITS}

\author{
by
}

D. E. Peterson and J. S. Starzynskj

\begin{abstract}
Two Light-Weight Radioisotope Heater Units (LWRHU) were exposed to thermal ramps simulating atmospheric reentry. The helium release rates were measured during each test and modeled after simple diffusion theory. The reentry pulses did not result in swelling of the claddings or degradation of the fuel pellets.
\end{abstract}

\section{INTRODUCTION}

The Light-Weighi Radioisotope Weater Unit (LWRHU) was designed by the Los Alamos National Laboratory' to warm instrumentation on interplanetary satellites. The first application of the unit is on the Galileo Mission to Jupiter. During an accidental reentry into the Earth's atmosphere, a LWRHU would be exposed to a thermal ramp in which a fuel temperature above $1600^{\circ} \mathrm{C}$ could be attained within a few minutes. To determine the response of a LWRHU to this severe treatment and to provide data useful in theoretical modeling, the reentry simulation tests described in this report were performed.

A schematic of a LWRHU capsule is shown in Fig. 1. The fuel is a 238-plutonium dioxide pellet (weighing about $2 \mathrm{~g}$ ) encapsulated in iridium. The fuel capsule is contained within a graphite impact shell. Gases released from the fuel pass through a vent assembly consisting of a frit (scrving as a particulate filter) and an orifice (0.6mm diam).

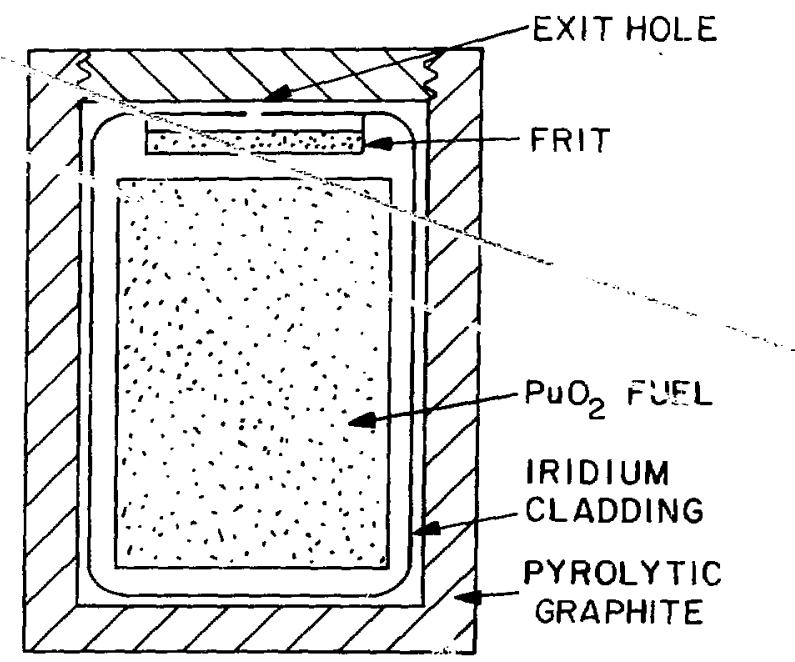

Fig. 1. Schematic of a Light Weight Radioisotopic Heater Unit (LWRHU). 
Helium is being continuously generated by alpha decay of the ${ }^{238} \mathrm{Pu}$ isotope. Under storage or operating conditions assocjated with a LWRHU, most of the helium is retained within the fuel lattice. When a LWRHU is subjected to a simulated atmosphericreentry thermal pulsen the stored helium is released in a burst that can have several negative effects: (1) The integrity of the fuel body can be degraded, leading to additional fines generation upon impact. (2) The associated pressure buildup within an improperly vented LWRHU cansule could result in swelling of the cladding and compromise the fuel containment. (3) Finally, the released helium can fill the insulator gaps, leading to an unacceptable rise in the clad ternperature. To test for these effects and to provide data useful in modeling a LWRHU reentry, we performed the experiments described herein.

The study was conducted by applying a simulated reentry ramp to fuel pellets (aged over seven years) contained in actual LWRHU components. Thermal reentry ramps were applied to two LWRHUs, during which the helium release rates were measured as functions of time and temperature. A semiempirical model, assuming simple diffusion, was used to analyze the release behavior. We measured the extent of swelling of the capsules, determined the fuel integrity, and analyzed the residual helium content of the fuel.

\section{THEORY}

The helium release rates measured in this study were analyzed based on Fick's laws of simple diffusion, an approach previously discussed by Peterson and Frantz. ${ }^{2}$ Using the fractional release, $F$, as a function of time, we calculated an effective diffusion constant, $D^{\prime}\left(=D / a^{2}\right.$, where $a$ is the effective radius of the releasing unit). Variations in $\mathrm{D}^{\prime}$ with temperature and therefore time, $t$, are accounted for by using the parameter, $\tau$, defined as

$\tau=\int_{0}^{t} D^{\prime} d t$

Assuming that Fick's laws of diffusion apply, one can derive the exprossion

$$
F=1-\frac{6}{\pi^{2}} \sum_{n=1}^{\infty} \frac{1}{\pi^{2}} \exp \mid-n^{2} \pi^{2} \tau j,
$$

from which a value of $\tau$ may vindermined at a timc, $!$ from a corresponding $F$ value. Thus a $i$ ime curve is generated that has a derivative at any point equivalent to the effective diffusion constant.

The temperature dependence of $D^{\prime}$ was used in Eq. (3) to obtain an activation energy, $E_{b}$, a constant for diffusion, $D_{0}^{\prime}$, and the gas constant, $R$.

$\mathrm{D}^{\prime}=\mathrm{D}_{0}^{\prime} \exp \left|-\mathrm{E}_{\mathrm{B}} / \mathrm{RT}\right|$

The magnitude of the activation energy provides an indication of the energy barrier for diffusion of the helium atoms within the plutonia lattice.

\section{EXPERIMENTAL}

The reentry simulations were performed with the apparatus depicted in Fig. 2. The Centorr furnace was heated by a tungsten mesh element and the system was evacuated with an oil diffusion pump containing a liquid nitrogen trap and backed by a forepump. A CEC leak detector was connected to the furnace with a leak valve apportioring the helium released between the detector and the furnace. A picoammeter amplified the signal from the leak detector, which was displayed on an $x-y$ recorder containing an internal time base. The helium release rate was calibrated with a Teledyne-Hastings flowmeter prior to the reentry simulated pulse. Tank

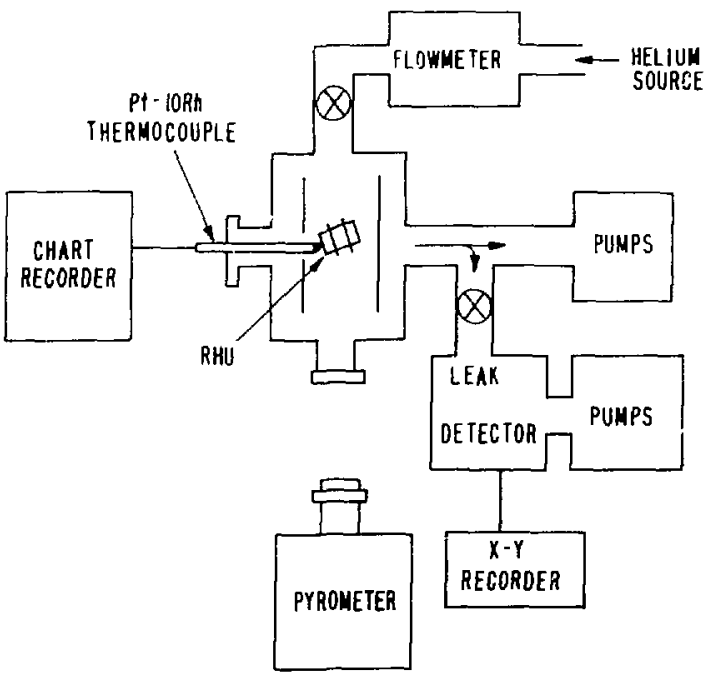

Fig. 2. Apparatus for study of helium release from radioisotopic hicater units. 
helium was flowed into the furnace through the fowmeter over a range of 9 to $24 \mathrm{cc}(\mathrm{STP}) / \mathrm{min}$. This range corresponded to anticipated helium release rates from plutonia pellets based on previous helium release measurements. ${ }^{3.4}$ The flowmeter reading was correlated with the leak detector signal. The leak valve between the furnace and the detector was set so as not to nood the detector at the highest helium release rate.

The LWRHU temperature was determined with a Pt$\mathrm{Pt} /$ IORh thermocouple touching the capsule base. The temperature readings were ccntinuously monitored with a Brown chart recorder, the range of which was calibrated with a millivolt power source. The thermocouple readings were correlated with temperatures measured simultaneously with a Leeds and Northrup automatic pyrometer sighted onto the LWRHU wall. The desired temperature ramp was achieved by manually adjusting the power level to the heating element. An LWRHU fueled with a plutonia pellet was used to optimize the temperature ramp. The reentry ramps actually applied were significantly more severe than the reentry pulse (AP2737) calculated at Applied Physics Laboratory.

Two sets of ${ }^{238} \mathrm{PuO}_{2}$ pellets (14367), weighing 1.90 and $2.10 \mathrm{~g}$, were selected from a batch that had been aged for 7.83 and $7.93 \mathrm{yrs}$, respectively. These peliets were encapsulated in LWRHUs designated 004 and 027. Prior to encapsulation the vent assemblies had flow rates of 12.4 and $6.57 \mathrm{~mole} / \mathrm{sec} / \mathrm{atm}$, respectively, as measured at Mound Facility. Each LWRHU was placed on a Pt-10Rt stand in the center of the furnace and the system evacuated to $1 \times 10^{-4}$ torr. The temperature was increased to $400^{\circ} \mathrm{C}$ and allowed to stabilize at this temperature for one hour. Each LWRHU was then subjected to the simulated reentry pulse.

\section{RESULTS}

Exposure of the LWRHU 004 to the reentry ramp resulted in flooding of the leak detector. The temperature and detector levels are shown as a function of time in Table I. A large helium signal was noted at $850^{\circ} \mathrm{C}$, and detector flooding occurred at about $1270^{\circ} \mathrm{C}$.

The leak valve was partially closed and the furnace recalibrated. The time dependence of the helium release from LWRHU 027 is shown in Fig. 3. Also displayed are the measured and calculated temperature ramps. The first detectable helium signal was noted at $910^{\circ} \mathrm{C}$ with the release rate maximizing at $1288^{\circ} \mathrm{C}$. The values
Table I. Temperatures and Leak Rates Measured During Exposure of RHU 004 to a Thermal Reentry Pulse.

\begin{tabular}{rc}
\hline$T\left({ }^{\circ} \mathrm{C}\right)$ & Leak Rate \\
\hline & \\
436 & 0.13 \\
659 & 0.30 \\
846 &.-- \\
1023 & 120.0 \\
1266 & 160.0 \\
1567 & 120.0 \\
1580 & 120.0 \\
1515 & 50.0 \\
\hline
\end{tabular}

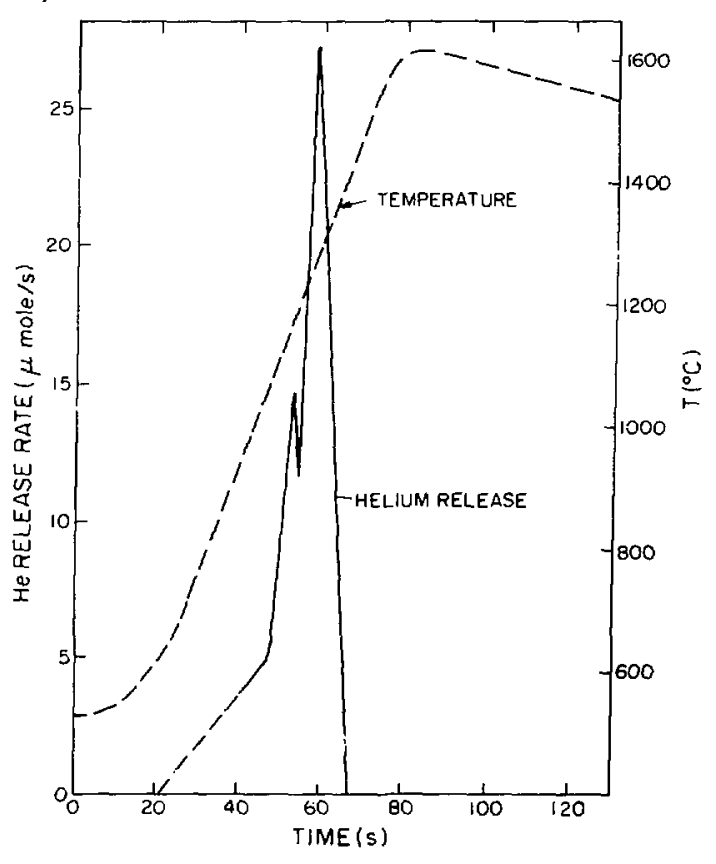

Fig. 3. Time dependence of helium release and temperature in reentry simulation of RHU 027. 
corresponding to the measured temperatures and release rates are given at $1-\mathrm{sec}$ intervals in Table II.

The helium inventory contained in each set of pellets was calculated from the alpha decay rate as given by the equation,

$$
\mathrm{n}=3.70 \mathrm{i} \times 10^{-3}\left(1-\mathrm{e}^{-0.00791}\right)(\mathrm{G})(\mathrm{P})
$$

where $\mathrm{n}=$ helium amount (moles),

$$
\begin{aligned}
\mathrm{t} & =\text { time }(\mathrm{yrs}), \\
\mathrm{G} & =\text { mass } \mathrm{PuO}_{2}(\mathrm{~g}), \text { and } \\
\mathrm{P} & =\text { per cent }{ }^{238} \mathrm{Pu} \text { enrichment } / 100=0.800 .
\end{aligned}
$$

The total helium levels ealculated for LiNRHUs 004 and 027 were 337 and $378 \mu$ mole, respectively. The residual helium levels analyzed following reentry were 17 and $49 \mu$ mole, respectively, correlating with a total release of 95 and $87 \%$ of the helium inventories. Integration of the total helium released from LWRHU 027 gave $330 \mu \mathrm{mole}$, or $88 \%$ of the calculated inventory.

The values of the fractional helium released, the logarithm of the effective diffusion constant, and the reciprocal temperature used in modeling the release behavior of LWRHU 027 are given in Table III. A plot of the $\log D^{\prime}$ vs the reciprocal temperature is shown in Fig. 4. There appears to be a definite break at about $1100^{\circ} \mathrm{C}$. Least-squares analysis performed on the two respective data sets yielded the results shown in Table $I V$, where the slope and intercept of each line is given along with the corresponding activation energy, $E_{a}$, and constant for diffusion. $\mathrm{D}_{0}^{\prime}$.

The external dimensions of LWRHUs 004 and 027 measured before and after the reentry pulses are given in Table V. No swelling of either capsule from the reentry pulse was evident. Each capsule top was sawed off and the vent and fuel pellets examined. The ven a assemblies showed no degradation nor any evidence of vapor transport in the frits or vent holes. Fuel-pellet integrity appeared to be excellent following the reentry.

Based on the alpha-decay rate, approximately 8.2 and $8.46 \mathrm{cc}(\mathrm{STP})$ of helium were calculated to have been resident in the fuel of LWRHUs 004 and 027. Following

\begin{tabular}{|c|c|c|c|c|c|c|c|c|}
\hline $\begin{array}{l}\text { Time } \\
(\mathrm{sec})\end{array}$ & $\begin{array}{l}\text { Temp } \\
\left({ }^{\circ} \mathrm{C}\right)\end{array}$ & $\begin{array}{c}\text { Rate } \\
(\mu \mathrm{mole} / \mathrm{sec})\end{array}$ & $\begin{array}{l}\text { Time } \\
\text { (sec) }\end{array}$ & $\begin{array}{l}\text { Temp } \\
\left({ }^{\circ} \mathrm{C}\right) \\
\end{array}$ & $\begin{array}{c}\text { Rate } \\
(\mu \mathrm{mole} / \mathrm{sec})\end{array}$ & $\begin{array}{l}\text { Time } \\
(\mathrm{sec})\end{array}$ & $\begin{array}{l}\text { Temp } \\
\left({ }^{\circ} \mathrm{C}\right)\end{array}$ & $\begin{array}{c}\text { Rate } \\
(\mu \text { mole/sec })\end{array}$ \\
\hline 0 & 528 & -- & 37 & 865 & 2.3387 & 57 & 1235 & 18.410 \\
\hline 5 & 535 & -- & 38 & 883 & 2.5786 & 58 & 1254 & 21.408 \\
\hline 10 & 552 & --- & 39 & 901 & 2.7585 & 59 & 1272 & 26.805 \\
\hline 15 & 578 & $\cdots$ & 40 & 919 & 2.9983 & 60 & 1291 & 25.905 \\
\hline 20 & 620 & $\cdots$ & 41 & 938 & 3.2982 & 61 & 1311 & 22.607 \\
\hline$? 2$ & 637 & $--\cdot$ & 42 & 956 & 3.5980 & 62 & 1330 & 19.409 \\
\hline 23 & 663 & 0.00090 & 43 & 974 & 3.7779 & 63 & 1350 & 15.411 \\
\hline 24 & 674 & 0.17990 & 44 & 992 & 4.0177 & 64 & 1369 & 11.813 \\
\hline 25 & 685 & 0.26985 & 45 & 1010 & 4.4506 & 65 & 1389 & 8.8149 \\
\hline 26 & 695 & 0.41976 & 46 & 1029 & 4.7973 & 66 & 1408 & 6.7162 \\
\hline 27 & 706 & 0.53970 & 47 & 1048 & 5.0971 & 67 & 1428 & 5.5169 \\
\hline 28 & 717 & 0.68961 & 48 & 1066 & 5.4840 & 68 & 1447 & 3.7179 \\
\hline 29 & 727 & 0,83953 & 49 & 1085 & 6.4164 & 69 & 1463 & 1.9189 \\
\hline 30 & 738 & 0.98952 & 50 & 1104 & 7.4355 & 70 & 1482 & --- \\
\hline 31 & 756 & 1.1394 & 51 & 1122 & 9.4146 & 75 & 1551 & --- \\
\hline 32 & 774 & 1.3193 & 52 & 1141 & 10.014 & 80 & 1586 & --- \\
\hline 33 & 792 & 1.5291 & 53 & 1160 & 13.838 & 85 & 1606 & --- \\
\hline 34 & 811 & 1.7390 & 54 & 1179 & 13.312 & 90 & 1610 & -- \\
\hline 35 & 829 & 1.9189 & 55 & 1197 & 11.813 & 95 & 1605 & --- \\
\hline 36 & 847 & 2.1588 & 56 & 1216 & 14.212 & 100 & 1596 & -- \\
\hline
\end{tabular}
reentry, residual helium levels of 0.4 and $1.1 \mathrm{cc}$ remained

Table II. Times, Temperatures, and Helium Release Rates Associated with Thermal Reentry Pulse Given LWRHU 027. 
Table III. Release Integral and Diffusion Constant Calculated for Reentry of LWRHU 027 as a Function of Time and Reciprocal Temperature.

\begin{tabular}{cccccccc}
\hline $\begin{array}{c}\text { Time } \\
\text { (sec) }\end{array}$ & $\begin{array}{c}\text { Release } \\
\text { Integral }\end{array}$ & $\begin{array}{c}\text {-log } \mathbf{D}^{\prime} \\
\left(\text { sec }^{-1}\right)\end{array}$ & $\begin{array}{c}10^{4} / \mathrm{T} \\
\left(\mathrm{K}^{-1}\right)\end{array}$ & $\begin{array}{c}\text { Time } \\
(\mathrm{sec})\end{array}$ & $\begin{array}{c}\text { Release } \\
\text { Integral }\end{array}$ & $\begin{array}{c}-\log \mathrm{D}^{\prime} \\
\left(\mathrm{sec}^{-1}\right)\end{array}$ & $\begin{array}{c}10^{4} / \mathrm{T} \\
\left(\mathrm{K}^{-1}\right)\end{array}$ \\
\hline & & & & & & & \\
22 & 0 & 0 & 10.99 & 49 & 0.17326 & 3.135 & 7.36 \\
30 & 0.01064 & 5.261 & 9.89 & 50 & 0.19295 & 3.017 & 7.26 \\
31 & 0.01366 & 5.083 & 9.72 & 51 & 0.21788 & 2.853 & 7.17 \\
32 & 0.01715 & 4.916 & 9.56 & 52 & 0.24440 & 2.762 & 7.07 \\
33 & 0.02120 & 4.755 & 9.39 & 53 & 0.31629 & 2.490 & 6.89 \\
34 & 0.02580 & 4.609 & 9.23 & 54 & 0.31629 & 2.490 & 6.89 \\
35 & 0.03089 & 4.482 & 9.08 & 55 & 0.34757 & 2.477 & 6.80 \\
36 & 0.03660 & 4.354 & 8.93 & 56 & 0.38521 & 2.332 & 6.72 \\
37 & 0.04279 & 4.246 & 8.79 & 57 & 0.43395 & 2.142 & 6.63 \\
38 & 0.04962 & 4.135 & 8.65 & 58 & 0.49064 & 1.984 & 6.55 \\
39 & 0.05693 & 4.041 & 8.52 & 59 & 0.56162 & 1.774 & 6.47 \\
40 & 0.06487 & 3.944 & 8.39 & 60 & 0.63021 & 1.661 & 6.39 \\
41 & 0.07360 & 3.843 & 6.26 & 61 & 0.69007 & 1.590 & 6.32 \\
42 & 0.08313 & 3.748 & 8.14 & 62 & 0.74279 & 1.507 & 6.23 \\
43 & 0.09313 & 3.672 & 8.02 & 63 & 0.78360 & 1.471 & 6.16 \\
44 & 0.10377 & 3.592 & 7.91 & 64 & 0.81488 & 1.432 & 6.09 \\
45 & 0.11555 & 3.496 & 7.79 & 65 & 0.83822 & 1.392 & 6.02 \\
46 & 0.12703 & 3.459 & 7.68 & 66 & 0.85600 & 1.321 & 5.95 \\
47 & 0.14175 & 3.300 & 7.57 & 67 & 0.87062 & 1.160 & 5.88 \\
48 & 0.15627 & 3.255 & 7.47 & 68 & 0.88046 & 0.962 & 5.81 \\
\hline
\end{tabular}

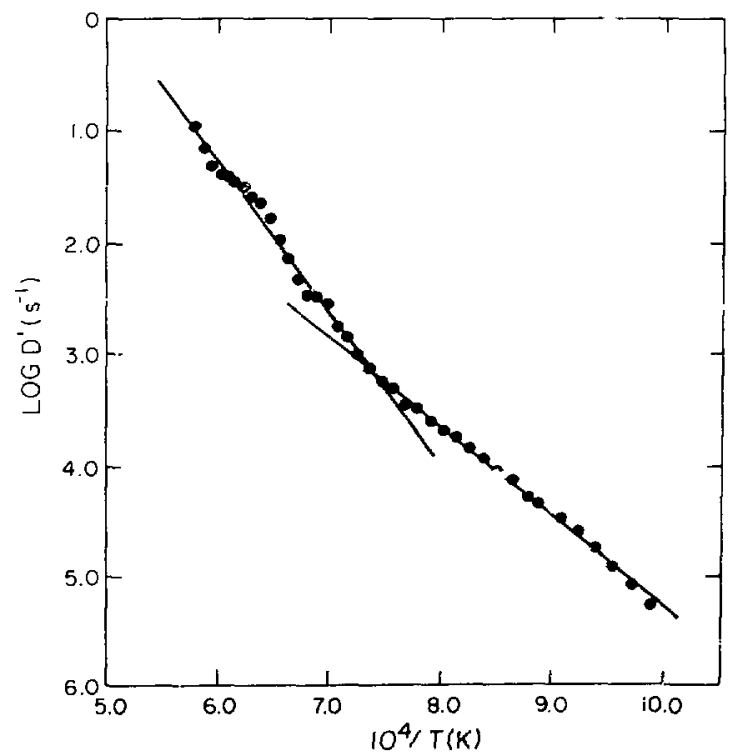

Fig. 4. Plot of $\log D^{\prime}$ vs the reciprocal temperature determined from anaiysis of RHU 027 . 


Table IV. Slopes and Intercepts of Log $\mathrm{D}^{\prime}$ vs $1 / \mathrm{T}$ Plots for Low- and High-
Tempcrature Regions. Corresponding Activation Energies, $\mathrm{E}_{\boldsymbol{g}}$,
and Constants of Diffusion, $\mathrm{D}_{0}^{\prime}$, are Also Listed.

Parameter Low Temperature High Temperature

\begin{tabular}{|c|c|c|c|c|}
\hline No. pts. & & 19 & & 20 \\
\hline T range $\left({ }^{\circ} \mathrm{C}\right)$ & 727 & -1104 & 1066 & -1447 \\
\hline Slope & -8073.8 & \pm 120.0 & -13667.1 & \pm 386.7 \\
\hline Intercept $\left(\log D_{0}^{\prime}\right)$ & 2.8096 & 亡 0.1033 & 6.9355 & \pm 0.2535 \\
\hline $\mathrm{E}_{\mathrm{s}}(\mathrm{KJ})$ & 154.6 & \pm 2.3 & 261.7 & \pm 7.4 \\
\hline
\end{tabular}

in the fuel pellets of the respective LWRHUs as determined by high-temperature collection and mass spectrometry. These levels correlate to releeses of 95 and $87 \%$ of the total helium inventories, the latter value agreeing well with the $88.5 \%$ determined from the total release measured during the ramp of LWRHU 027.

\section{DISCUSSION}

The helium release rates measured from both LWRHUs were higher than anticipated, based on previous measurements on microspheres or pellets. ${ }^{3.4}$ The detector flooding in the LWRHU 004 reentry was unexpected and shows the very fast release of the stored helium during exposure to thermal pulse. This experiment yielded approximate temperatules at which the helium release began and maximized, as well as an estimate of the maximum release rate.
The leak valve between the detector and furnace was set to detect the onset of helium release while still not flooding the detector at the maximum release rate. The $\mathrm{x}$ $y$ recorder went slightly off scale during the LWRHU 027 reentry simulation but fortunately made a fast recovery. During this period of flooding the helium release was determined by extrapolation of the rate vs time rur.e.

The tests performed in this study were overtests of the actual reentry of an LWRHU. The simulated reentry pulses were significantly more severe than the worst case reentry ramp calculated at the Applied Physics Laboratory, the temperature rise being significantly steeper and the maximum temperature over $100^{\circ}$ higher. The vent rates extended down to the minimum specification of $0.45 \mu \mathrm{mole} / \mathrm{sec}^{\prime}$

The naximum storage period anticipated for LWRHU fuel is $4.5 \mathrm{yrs}$ whereas the fuel used in this study was over 7 yrs old. Therefore, the internal pressure

\begin{tabular}{|c|c|c|c|c|}
\hline \multirow[b]{2}{*}{ Parameter } & \multicolumn{2}{|c|}{ LWRHU-004 } & \multicolumn{2}{|c|}{ LWRHU-027 } \\
\hline & $\begin{array}{l}\text { Before } \\
\text { (mm) }\end{array}$ & $\begin{array}{l}\text { After } \\
(\mathrm{mm})\end{array}$ & $\begin{array}{l}\text { Before } \\
(\mathrm{mm})\end{array}$ & $\begin{array}{l}\text { After } \\
\text { (mm) }\end{array}$ \\
\hline Length & 12.475 & 12.460 & 12.500 & 12.500 \\
\hline Upper diam & 8.300 & 8.310 & 8.290 & 8.305 \\
\hline Upper Land diam & 8.515 & 8.540 & 8.530 & 8.535 \\
\hline Lower Land diam & 8.575 & 8.575 & 8.570 & 8.565 \\
\hline Lower diam & 8.350 & 8.355 & 8.330 & 8.335 \\
\hline
\end{tabular}


build-up of helium must be greater in our test cases. The absence of any observable swelling of the LWRHJ capsules indicates that the vent assemblies can handle the helium released during the atmospheric reentry conditions.

Any pumping rate effects from the helium release during the ramp would have been offset by the calibration. Most background gases emitted by the system or LWRHU would have been pumped off during the initial heating period at $400^{\circ} \mathrm{C}$. Very little change was noted in the furnace pressure while optimizing the reentry ramp, which supports the lack of background gas effects. The helium flow calibration performed at ambient temperature was related to the release rates measured at temperatures associated with the thermal pulse. The effect of these temperature differences on the helium release rates determined in this study are believed to be negligible because of the low pressures involved.

Almost the entire helium inventory was released during the experimental ramps. The difference in the total amounts released during the two reentries was most likely the result of a more severe ramp in the LWRHU 004 exposure. The temperature during this ramp was not controlled and monitored as carefully as in the subsequent pulse given LWRHU 027.

It is interesting to note that the fuel pellets survived the reentry pulses intact, even after being subjected to severe temperature excursions and burdened with a relatively large helium inventory. The break observed in the $\log D^{\prime}$ vs $1 / \mathrm{T}$ curve at about $1100^{\circ} \mathrm{C}$ is not unusual; Mulford and Mueller $^{3}$ observed similar discontinuities in the temperature dependence of the diffusion coefficient, as did Angelini and coworkers. ${ }^{4}$ Diffusion of the helium through the grains, with entrapment at the grain boundaries, probably predominates at temperatures below $1100^{\circ} \mathrm{C}$, but at higher temperatures, the helium trapped in the grain boundaries wou'd be released, accounting for thi break. The activation energy of $261 \mathrm{~kJ}$ agrces well with the value of $282 \mathrm{~kJ}$ determined during the heat treatment ${ }^{2}$ of the General Purpose Heat Source capsule, IRG-62.

\section{REFERENCES}

1. R. E. Tate, "The Light Weight Radioisotope Heater Unit (LWRHU). A Technical Description of the Reference Design," Los Alamos National Laboratory report LA-9078-MS (December 1981).

2. D. E. Peterson and C. E. Frantz, "Reentry Thermal Testing of a General Purpose Heat Source Fueled Clad." Los Alamos National Laboratory report LA-9227 (March 1982).

3. R. N. R. Mulford and B. A. Mueller, "Measurements of Helium Release from Materials Containing ${ }^{238} \mathrm{PuO}_{2}$," Los Alamos National Laboratory report LA-5215 (July 1973).

4. P. Angelini, R. E. McHenry, J. L. Scott, W. S. Ernest, and J. W. Prados, "Helium Release from ${ }^{238} \mathrm{PuO}_{2}$ Microspheres," Oak Ridge National Laboratory report ORNL-4507 (March 1970).

\section{ACKNOWLEDGMENTS}

We would like to recognize D. Pavone of CMB-5 for providing the plutonia pellets for these tests. The support of the Department of Energy, Office of Coordination and Special Projects is also appreciated. 